\title{
Argentina y Brasil en la Política Internacional: regionalismo y Mercosur (estrategias, cooperación y factores de tensión)
}

\author{
Argentina and Brazil in the Internacional Politics: regionalism \\ and Mercosur (strategy, cooperation and factors of tension)
}

RAÚL BERNAL-MEZA*

Rev. Bras. Polít. Int. 51 (2): 154-178 [2008]

\section{Algunas consideraciones teóricas}

La integración económica - hoy crecientemente considerada dentro del "regionalismo" o la "regionalización" es una estrategia destinada a fortalecer el desarrollo económico, la acumulación de recursos de poder o ambos; la primera interpretación desde la perspectiva del desarrollismo-cepalismo; la segunda desde la teoría realista de las relaciones internacionales.

La regionalización promueve fuerzas centrípetas que tienden a integrar en un mismo espacio regional a países geográficamente próximos y económicamente complementarios, por lo menos en lo que respecta a la acumulación de recursos y en el aumento de las dimensiones del mercado y está inevitablemente vinculado al ámbito multilateral y al orden mundial, porque todo proceso particular de regionalización genera repercusiones sistémicas por los alineamientos estratégicos que producen los países que construyen la región y que modifican la situación relativa de éstos en la economía mundial y, porque conllevan estrategias de alianzas que inciden y/o determinan el curso de negociaciones multilaterales (BernalMeza y Masera, 2008). Los países se plantean la posibilidad de participar en un proceso de integración regional porque prevén que con esta agrupación pueden obtener mayores beneficios políticos y económicos que si continúan aislados. En este sentido, la percepción de que en un mundo globalizado, las economías pueden ser más dinámicas y competitivas, con mayor poder de negociación y de inserción internacional si cooperan con otras, se relaciona con el aumento de la conciencia regional (Hurrell, 1994).

*Profesor Titular de Relaciones Internacionales de la Universidad Nacional del Centro de la Provincia de Buenos Aires y Profesor de la Universidad de Buenos Aires, Argentina (bernalmeza@hotmail.com). 
El regionalismo en América Latina ha oscilado históricamente entre dos polos: por un lado, mediante el desarrollo de esquemas de integración intralatinoamericanos sin presencia de los Estados Unidos de América, y por otro, con el establecimiento de ámbitos de cooperación bajo la égida norteamericana (conferencias Panamericanas, proyecto ALCA). En el primer caso, los Estados Unidos de América, tal como ha sostenido Hurrell ${ }^{1}$, han intentado históricamente desestabilizar a los esquemas latinoamericanos en sus intentos de lograr una cierta autonomía en su trayectoria. De igual modo, puede ser analizado bajo el sentido en que el MERCOSUR es un ámbito de cooperación e integración que permite lograr un equilibrio frente a otros espacios regionales, como el NAFTA y la Unión Europea.

De acuerdo a modelos analíticos que hemos desarrollado (Bernal-Meza, $2000 ; 2003 ; 2004)$, para analizar la estrategia de integración de cada país es necesario poner ésta contra el telón de fondo de la política exterior, porque ella es una e indivisible, y confrontar ambas con el modelo de desarrollo nacional o de inserción internacional.

\section{El MERCOSUR como modelo de regionalización: entre el libre cambio y la unión aduanera.}

El escenario político en el cual ambos países hoy cooperan y formulan estrategias comunes es el MERCOSUR. Un proyecto creado por ellos dos, que hoy es el cuarto bloque comercial del mundo.

El MERCOSUR representa el ejemplo de regionalismo/regionalización más exitoso de la historia económico-política de la América del Sur contemporánea y es la primera - si bien imperfecta - unión aduanera del continente. Pero, antes que un programa comercial y económico, es un proyecto político, tanto por sus antecedentes, como por su proyección en la economía política mundial

Fundado en 1991, por el Tratado de Asunción, bajo el impulso de los presidentes Collor de Mello y Carlos Menem y proyectado con el objetivo de crear un mercado común entre cuatro país (Argentina, Brasil, Uruguay y Paraguay), por el Protocolo de Ouro Preto (1994), ha pasado desde entonces por distintas etapas. A pesar de que tal vez no se hayan cumplido todas las expectativas, el Acuerdo tiene un fuerte vínculo con la paz y la cooperación en el Cono Sur de América Latina.

A partir de la experiencia y los progresos conseguidos mediante los acuerdos argentino-brasileños de 1986, impulsados por los respectivos gobiernos de Alfonsín y Sarney, bajo el PICAB (Programa de Integración y Cooperación Argentino-Brasileño, 1988), el MERCOSUR continuó una línea de cooperación

1 (HURRELL, Andrew (1994): "Regionalismo en las Américas", en LOWENTHAL, Abraham y TREVERTON, Gregory (comps.), América Latina en un Mundo Nuevo, México D.F., Fondo de Cultura Económica, pp. 199-226). 
e integración que, si bien modificó su perfil en el marco de la economía política - al pasar de una concepción industrialista basada en el modelo de sustitución de importaciones, como era el proyecto de 1986, a una concepción comercialista, basada en el modelo de "regionalismo abierto" de apertura, en 1991 - se transformó en un instrumento clave para el impulso de la paz y la cooperación. Esto hizo del Atlántico Sur, que ambos países comparten, una "Zona de Paz" porque fueron abandonadas las hipótesis de conflicto entre los dos más grandes países sudamericanos, las que habían predominado por más de cien años.

La construcción de esta "región" denominada MERCOSUR, descansó en elementos comunes que estos dos país y luego los otros dos países incorporados plenamente (Uruguay, Paraguay), así como los asociados (Chile, Bolivia), comparten: la proximidad (sobre la base de factores comunes previos como la cercanía geográfica; vínculos históricos y culturales, etc.); valores fundamentales (como la promoción y preservación de la democracia como sistema político; el desarrollo socioeconómico regional; la industrialización; el crecimiento económico redistributivo y la transformación productiva regional con equidad); estrategias comunes de governanza y accountability; ampliación de la participación social, económica y política de las comunidades y agentes y actores económicos y sociales, etc.

La mayoría de los supuestos señalados teóricamente por Balassa sobre la integración económica se dieron, con diferentes prioridades, en las distintas etapas por las que pasó el MERCOSUR en estos 17 años: la creación de comercio; la generación de un mayor nivel de competencia intra-bloque; el aprovechamiento de economías de escala; la cooperación intra-regional en proyectos de innovación tecno-industriales asociados; una más eficiente y mejor racionalización de la producción mediante una división regional de la industria; la generación de mecanismos de financiamiento regional; la complementación económica; y, por ultimo, la sinergia en los frentes de negociación internacional (Balassa, 1980).

Elementos propios de la "cooperación" también se han mantenido caracterizando el proceso de una forma sui generis, como la existencia de distintos sistemas monetarios, fiscales, de seguridad social y hasta con una visión completamente distinta de la organización de la empresa y los mercados; éstos han coexistido con características tales como el acercamiento progresivo de los países con el fin de eliminar restricciones comerciales, discriminaciones o diferenciaciones (normas técnicas, medios de pago, etc.) y las trabas a la movilidad de los factores productivos.

Esta regionalización - que supone en teoría poner en contacto economías relativamente homogéneas y de nivel de desarrollo relativo comparable, en camino de un acoplamiento progresivo de las estructuras socio-económicas; la convergencia política, a fin de crear instituciones comunes que permitan seguir, cuando sea necesario, una política coordinada en los ámbitos monetarios, financieros, industriales, comerciales, etc;) - aunque su énfasis se encuentra 
en los aspectos económicos no es puramente económico, sino simultánea y sistémicamente, político, social y cultural (Bernal-Meza, 2000).

Pero, la enorme diferencia en las dimensiones geográficas, demográficas y del PBI, puso de relevancia el peso relevante del Brasil, respecto de sus socios, y sus esfuerzos por mantener la autonomía de la decisión de políticas nacionales por sobre la creación de instituciones comunitarias.

Brasil y Argentina, desde la creación del MERCOSUR, han seguido políticas exteriores y modelos de inserción internacional a veces coincidentes y por épocas sustancialmente distintos, aún cuando en el caso brasileño, ambas políticas han sido más constantes y, en el caso argentino, más erráticas. En este sentido, los objetivos que Brasil ha perseguido en el MERCOSUR y a través de éste, aparecen - para este autor - claramente, aún cuando los mismos no hayan sido reconocidos explícitamente por representantes gubernamentales de ese país.

Bolivia, Chile, Colombia, Ecuador y Peru tienen status de miembros asociados, mientras que Venezuela firmó su acuerdo de membrecía el 17 de Junio de 2006, pero para llegar a ser miembro pleno del acuerdo su ingreso deberá ser ratificada aún por los parlamentos de Brasil y Paraguay, países donde existe cierta oposición al ingreso de Venezuela.

El proceso hacia la constitución de un mercado común ha sido difícil. Entre sus principales hitos están:

- El 18 de febrero de 2002, mediante el Protocolo de Olivos para la Solución de Controversias se crea el Tribunal Permanente de Revisión del Mercosur. Se instaló en 2004 con sede en Asunción.

- El 6 de diciembre de 2002, los miembros plenos del Mercosur, más Bolivia y Chile, firman el Acuerdo de Residencia para Nacionales estableciendo la libertad de residencia y trabajo en todo el ámbito de los seis países.

- En 2003, por Decisión CMC No 11/03, se creó la Comisión de Representantes Permanentes del Mercosur (CRPM) con su Presidente. El Presidente de la CRPM representa al Mercosur ante terceros, y dura dos años en su cargo. Su actual presidente es el argentino Carlos Álvarez. designado para el período 2005-2007.

- En diciembre de 2004, en la Cumbre de Presidentes de Ouro Preto: se estableció el Fondo para la Convergencia Estructural del Mercosur (FOCEM) (Decisión CMC No 45/04), con el fin de financiar programas de convergencia estructural, competitividad, cohesión social, e infraestructura institucional; se creó el Grupo de Alto Nivel (GAN) para la formulación de una Estrategia MERCOSUR de Crecimiento del Empleo (Grupo de Alto Nivel para el Empleo); se encomendó a la Comisión Parlamentaria Conjunta la redacción de una propuesta de Protocolo Constitutivo del Parlamento del Mercosur.

- El 6 de julio de 2005 se firmó el Protocolo de Asunción sobre Derechos Humanos del Mercosur. En la Cumbre de Presidentes de Montevideo 
de diciembre de 2005, se creó el Parlamento del Mercosur que deberá ponerse en funcionamiento antes del 31 de diciembre de 2006.

- En la Cumbre de Presidentes de Córdoba (Argentina) del 20 al 22 de julio de 2006: se integró Venezuela como miembro pleno del Mercosur; se aprobó la Estrategia Mercosur de Crecimiento del Empleo (Decisión CMC No 04/06); se creó el Observatorio de la Democracia del Mercosur (Decisión 24/06); se estableció que Argentina será sede permanente del Mercosur Cultural; el 21 de diciembre de 2006 Bolivia pidió su ingreso al Mercosur como Estado parte. Por Decisión CMC 35/2006 se incorporó al Guaraní como uno de los idiomas del Mercosur.

- En la Cumbre de Presidentes realizada en Mar del Plata el 18 de enero de 2007 se aprobó el pedido de Bolivia de integrarse al Mercosur creando un Grupo Ad Hoc para su implementación; los primeros once proyectos piloto del FOCEM (Fondo para la Convergencia Estructural del Mercosur).

- En la XXXIV Cumbre de Presidentes realizada en Montevideo entre los dias 1 al 18 de diciembre de 2007 se firmó el primer Tratado de Libre Comercio (TLC) desde su fundacion en 1991. Es el Tratado de Libre Comercio entre el Estado de Israel y el Mercosur.

- En diciembre de 2004 se decidió crear el Parlamento del MERCOSUR en la cumbre presidencial; dicha institución deberá contar con 18 representantes de cada país para el $2010 .^{2}$

Las principales relaciones externas del MERCOSUR se han desarrollado con la Unión Europea, aunque el objetivo convenido en 1995, para la creación de una asociación estratégica y de libre comercio, no ha podido aún alcanzarse. Las relaciones entre los dos bloques tienen su fundamento en el "Framework Cooperation Agreement", firmado en 1995, el cual da las pautas y los objetivos para preparar la asociación birregional entre los mismos.

La U.E. ha elaborado dos documentos sobre "Estrategia Regional" dedicado al MERCOSUR, (Regional Strategy Paper-RSP), a fin de elaborar un esquema de cooperación entre ambos espacios regionales durante el período 2007-2013. El RSP ha sido preparado siguiendo un proceso de consulta y participación que

2 Chile formaliza su asociación al Mercosur el 25 de junio de 1996, durante la X Reunión de Cumbre del Mercosur, en San Luis, Argentina, a través de la suscripción del Acuerdo de Complementación Económica Mercosur-Chile; Bolivia formalizó su adhesión en la XI Reunión de Cumbre del Mercosur, en Fortaleza (Brasil), el 17 de diciembre 1996, mediante la suscripción del Acuerdo de Complementación Económica Mercosur-Bolivia. A fines de 2006 formalizó su pedido de admisión como miembro pleno del Mercosur.

Perú formaliza su asociación al Mercosur en el 2003 por la suscripción del Acuerdo de Complementación Económica Mercosur-Perú (CMC No 39/03). Colombia, Ecuador y Venezuela formalizan su asociación al Mercosur el 2004 mediante la suscripción del Acuerdo de Complementación Económica Mercosur-Colombia, Ecuador y Venezuela (CMC No 59/04). Venezuela se integra como estado miembro, con plenos derechos y deberes, al firmar el Protocolo de adhesión al Mercosur el 4 de julio de 2006. Entre el 2004 y 2006 Venezuela era Estado asociado 
ha incluido numerosas consultas a los países miembros de la Unión Europea y a actores de la sociedad civil. La visión general que se desprende de los papers elaborados en la Unión Europea señalan que el MERCOSUR ha sido un espacio de integración que ha promovido ciertamente estrategias de paz y de estabilidad en la región, además de haber generado un alto nivel de diálogo político y de haber fortalecido la cooperación interna e internacional. De todos modos, los documentos europeos consideran que el MERCOSUR aún tiene debilidades y necesidades de profundización. Por ejemplo, se señala que tiene progresos muy limitados en torno a la realización concreta de la unión aduanera, así como deficiencias en la estructuración del mercado común. Y particularmente, se considera que el MERCOSUR, debe realizar un considerable progreso en torno al desarrollo de su institucionalidad. En suma, el MERCOSUR, según la óptica europea tiene que hacer frente a tres grandes desafíos: 1 - mejorar su proceso de toma de decisiones y su capacidad para implementar y reforzar una legislación común; 2 - lograr de una vez por todas el funcionamiento del mercado común, con todo lo que ello implica; 3 - incrementar la conciencia sobre la importancia del rol de la sociedad civil en la construcción de la integración regional.

\section{Política exterior, integración y cooperación en Brasil y Argentina:}

Ambos países, con algunos objetivos coincidentes de política exterior, no son homogéneos en sus estrategias externas.

Para analizar la política exterior del Brasil en relación a la integración regional y la cooperación (Unión de Naciones Suramericanas, UNASUR), hay que mirar en su propio interior; estudiar las concepciones y paradigmas predominantes en el período en estudio, que corresponde a la vigencia del MERCOSUR. En cambio, para analizar el caso de la Argentina, hay ver tanto la visión y el paradigma dominante en la visión del gobierno del momento y la relación triangular con Estados Unidos y Brasil.

\section{Brasil: regionalismo continental y acumulación de poder}

Desde la década de 1930 la política exterior brasileña identificó como uno de sus principales objetivos el favorecer las condiciones externas para contribuir al desarrollo nacional. Así, durante más de setenta años, el modelo de política exterior ha estado asociado al "desarrollo nacional", aún cuando las estrategias de política han sido a veces diferentes entre sí; en particular respecto de la relación con Estados Unidos. Predominantemente aliado a Washington desde 1902, desde mediados de los años de 1970 mantuvo una línea autónoma e independiente; más débil bajo los gobiernos de Collor y Cardoso, más fuerte bajo las gestiones de Franco y Lula. 
En esa línea de autonomía, destinada a alcanzar un reconocimiento como potencia regional estuvo la construcción de "parcerias estratégicas" con algunos Estados considerados similares en atributos y recursos y, también, la formulación de estrategias de cooperación e integración a nivel sudamericano. Dentro de éstas se ubicó el MERCOSUR.

En los primeros trabajos en que abordé la estrategia brasileña hacia este bloque (Bernal-Meza,1998;1999;2000;2001), señalé que en su política exterior habían objetivos económicos - vinculados con el desarrollo y la ampliación de su mercado - y objetivos políticos - relacionados con la búsqueda de poder.

Los formuladores de política que acompañaron a Collor de Mello en su estrategia de creación del MERCOSUR tenían claro objetivos cercanos al neoliberalismo. El bloque fue concebido como un instrumento para la redefinición de su inserción internacional, en el marco de una política de apertura económica (liberalización), iniciada por este presidente y continuada por las dos gestiones de F.H. Cardoso.

El primer desafío era pasar de una economía cerrada a otra más abierta y competitiva internacionalmente, aumentando el poder de negociación y la extensión de mercados por vía de la integración económica. La conformación de una amplia zona geoeconómica en el Cono Sur, formaba parte de una estrategia de posicionamiento político hemisférico: le otorgaba a Brasil prestigio y poder, permitiéndole un liderazgo frente a Estados Unidos y sus iniciativas hemisféricas, en particular la formación de ALCA (Free Trade for the Ameritas, FTAA), el proyecto de creación de una zona de libre comercio de las Américas. Estos elementos eran suficientes para sustentar las aspiraciones de las clases dirigentes brasileñas, en el sentido que Brasil fuera reconocido como una potencia regional, en la medida que el bloque se constituyera en un proyecto exitoso.

Sin embargo, el paradigma de política exterior que sostenía ese objetivo no fue homogéneo. Así, mientras Cardoso buscó ese reconocimiento participando de la visión multilateralista del ex presidente Bill Clinton, basado en el neoidealismo kantiano, Lula da Silva lo ha hecho bajo una visión realista de la política mundial, según la cual las principales potencias rivalizan por el poder mundial y no se reconoce la existencia de un unipolarismo explícito. ${ }^{3}$ Con su gobierno ha habido una profundización de las pretensiones de liderazgo, ahora a nivel global, bajo esa visión realista, que buscaba llevar a Brasil a ascender en la jerarquía del poder mundial y posicionarlo en los regímenes mundiales que expresan la configuración jerárquica del sistema internacional, en particular el Consejo de Seguridad de Naciones Unidas (Bernal-Meza, 2006). Pero, asimismo, la dirigencia política brasileña reconoce que requiere de un entorno favorable que apoye esa proyección. Tal entorno estaría dado por una red de integración y cooperación regionales que tuviera al Brasil como su eje central.

3 Para ampliar el desarrollo de estas visiones, cfr. Amado CERVO $(2002 ; 2007)$ y Raúl BERNAL-MEZA (2002; 2006; 2007). 
Un reconocido ex embajador brasileño ha señalado recientemente que "por definição, um país em desenvolvimento que aspira a uma mayor projeção externa - seja em âmbito regional, seja internacional - não tem os meios de conseguir tal objetivo sem o concurso de outros. Tal circunstância é um dos fatores que têm levado à multiplicação dos arranjos econômicos regionais. Eles podem contribuir para aumentar, ainda que em diferentes graus, o peso específico dos participantes individuais. Podem também ser utilizados para inhibir uma potência de dentro ou de fora da área de ejercer uma influência considerada excesiva em asuntos da regiāo" (Souto Maior, 2006:51).

La visión política brasileña del regionalismo, una vez que se abandonó la perspectiva liberal de Collor, ha sido muy diferente de aquella de los Estados Unidos - también de otros países sudamericanos como Chile-, tanto en su concepción como en sus objetivos e instrumentos. La visión brasileña del MERCOSUR fue construir a través del mismo un nuevo factor de poder, visà-vis la política hemisférica de Estados Unidos. Fue una estrategia alternativa, intermedia, entre la continuidad de su política económica nacionalista y la apertura, bajo una economía liberal predominante en el mercado mundial. Dentro del bloque sudamericano Brasil podía ejercer presiones proteccionistas que serían imposibles de llevar adelante en el marco de un acuerdo hemisférico como el proyecto norteamericano de crear una zona de libre comercio de Alaska a Tierra del Fuego (ALCA).

Hacia el final de su gobierno, F.H. Cardoso ya había puesto a Brasil en oposición a Estados Unidos, en relación a la negociación de un acuerdo hemisférico de libre comercio y separado a Sudamérica del resto de América Latina. En ese esfuerzo por hacer de Sudamérica el entorno natural del Brasil, impulsó en el año 2000 la creación de una "Comunidad Sudamericana de Naciones" (CSN), que era una forma más cooperativa del viejo proyecto del ex presidente Itamar Franco de crear un acuerdo de libre comercio sudamericano el ALCSA, de 1994. Brasil estableció con el MERCOSUR una línea divisoria en el hemisferio americano: mientras consideró a América Central y Caribe una zona de influencia norteamericana, puso a América del sur como zona de influencia del MERCOSUR. Esta visión sobre la existencia de una división entre una América bajo la hegemonía norteamericana y otra más independiente, cuyo eje debía ser el MERCOSUR fue profundizada por el gobierno de Lula da Silva.

Pero Lula da Silva iría aún más allá. Como reconoció un ex diplomático, "simplificadamente, pode-se dizer que a idéia-chave suibjacente à nossa atual política regional é a construção de uma base subcontinental tão ampla e sólida quanto possível, de modo a firmar a liderança brasileira na América do Sul, o que deveria facilitar, no âmbito mundial, o exercício de uma política de potência emergente" (Souto Maior, 2006:54). Para ello - y sin la aprobación de Argentina - puso al MERCOSUR como núcleo de una integración más amplia, atrayendo a la Comunidad Sudamericana de Naciones (el anterior Grupo Andino) y a 
aquellos otros que se habían mantenido fuera de los esquemas sudamericanos, como Chile 4 , Suriname y Guyana. Este es el origen de la actual Unión de Naciones Sudamericanas (UNASUR); un acuerdo de cooperación e integración más flexible, centrado en el desarrollo de la infraestructura - a través del proyecto IIRSA $^{5}$ - que conecte a todos los países sudamericanos y que, de acuerdo a evaluaciones publicadas, beneficia preferentemente al Brasil. ${ }^{6}$

Las aspiraciones del gobierno Lula, de reforzar la vocación internacional del país, sin ataduras que menoscabaran su capacidad de decisión autónoma sobre la economía nacional, crearon limitaciones al progreso institucional del Tratado de Asunción, a pesar de las sucesivas negociaciones.

A pesar de los objetivos estratégicos que el Brasil se ha propuesto con el MERCOSUR, paradójicamente, ese país mantiene la presunción de que puede asumir un liderazgo regional sin pagar costos económicos (Bernal-Meza, 2006). Sin embargo, para el proceso de integración el eje del MERCOSUR sigue siendo la relación Brasil-Argentina, cuestión que el gobierno de Lula se ha esforzado en dejar en evidencia, tanto en sus viajes fuera de la región como a la Argentina.

\section{Política regional y política mundial brasileña:}

La estrategia de construcción de un liderazgo en América del Sur, seguido por la diplomacia brasileña formó parte de un camino trazado hacia la gran política mundial. Las políticas fueron distintas: más liberal con Collor de Mello y, en parte F.H. Cardoso; más autonomista con Itamar Franco, en parte con F.H. Cardoso y, de manera homogénea y constante, por Lula da Silva. Entre 1993 y 2008, la diplomacia brasileña buscó implementar tanto la cooperación Sur-Sur, más tradicional, con los vecinos del continente sudamericano, como la internacional, con países considerados potencias regionales con relativa influencia y capacidad globales, tales como China, India, Rusia y África del Sur.

Para su política mundial, Brasil utilizó la construcción de relaciones preferenciales con países considerados como sus socios naturales ${ }^{7}$, como los instrumentos de integración y cooperación regionales que impulsó, tales el MERCOSUR y la UNASUR. Así, ya en 1996 Cardoso visitó África del Sur, oportunidad en que dio por iniciadas las negociaciones comerciales entre el

4 Nos referimos a una condición de "socio pleno", la cual Chile sólo ha mantenido con la Asociación Latinoamericana de de Integración (ALADI).

5 Integración de la Infraestructura Sudamericana; proyecto impulsado al final de su mandato por Fernando H. Cardoso.

6 Cfr. al respecto, Silvia QUINTANAR y Rodolfo LÓPEZ, "La integración de la infraestructura regional en América del Sur (IIRSA) y el eje MERCOSUR-Chile”, en Raúl BERNAL-MEZA y Suranjit Kumar SAHA, Economía Mundial y Desarrollo Regional, Buenos Aires, Nuevohacer/Grupo Editor Latinoamericano, 2006; pp. 219-241.

7 La construcción de las llamadas "parcerías estratégicas" ha sido estudiada por distintos autores; cfr.; A. LESSA (1998); A.C. VAZ (1999); R. BERNAL-MEZA (2000; 2002). 
MERCOSUR y ese país y un acuerdo-marco para la creación de un área de libre comercio entre ambos fue firmado por él mismo en 2000; en tanto Lula decidió la incorporación de los restantes miembros de la Unión Aduanera del África Austral al acuerdo bilateral en 2003. Lula también presentó la propuesta de viabilizar un acuerdo de libre comercio entre China y el MERCOSUR al iniciar su mandato y, el mismo año 2003, firmó un acuerdo-marco MERCOSUR-India. Más tarde, en 2005, firmó el acuerdo entre el MERCOSUR y el África Austral. También llevó a cabo la cumbre entre países sudamericanos y los países de la Liga Árabe, organizado por el gobierno brasileño bajo el auspicio de la Comunidad Sudamericana de Naciones, en 2004. Todos estos acuerdos han sido firmados en ausencia de presidentes argentinos.

Este dinamismo internacional de la diplomacia brasileña se complementa con su pretensión de conducir la OMC; su ansiada aspiración a integrar el Consejo de Seguridad; el liderazgo del Grupo de los 20 dentro de la OMC; en las negociaciones Unión Europea-Mercosur y, en tiempos más recientes, en la formación junto con la India del G-4, que busca negociar con los Estados Unidos y la Unión Europea una salida al impasse de la Ronda de Doha.

Sin embargo, la lógica de su estrategia global no es homogénea: en el caso de la cooperación Sur-Sur con los países sudamericanos, Brasil asume una estrategia cercana al patrón de hegemonía, mientras que en aquella Sur-Sur internacionalmultilateral, asume un comportamiento de liderazgo colectivo, en asociación con otros países igualmente system-affecting ${ }^{8}$, como India y China (Saraiva, 2007).

\section{Argentina. Una política exterior errática: del activismo de Menem al retraimiento de Kirchner}

Con una tradición histórica de predominante rivalidad hemisférica con Estados Unidos, los sucesivos gobiernos que han coexistido durante la vigencia del MERCOSUR, no han tenido similares posiciones respecto de las relaciones con Washington. Más aún, éstas han sido muy encontradas: entre un período de abierto y explícito alineamiento político, bajo las dos presidencias de Carlos Menem; un período intermedio donde la Argentina estuvo más bien volcada al interior como consecuencia de la crisis económico-financiera, bajo los gobiernos transitorios de Fernando De la Rúa y Eduardo Duhalde, para llegar a un nuevo período de distanciamiento, bajo las presidencias de Néstor Kirchner y la actual, Cristina Fernández de Kirchner.

Bajo las presidencias de Carlos Menem (1989-1999), que al igual que Collor y Cardoso, llevaría a su país por una política de apertura y desregulación

8 Es decir, que disponen de recursos suficientes para -junto a la actuación internacional activa- afectar el encaminamiento de ciertos temas de política internacional (LIMA, Maria Regina Soares de, "A politica externa brasileira e os desafios da cooperação sul-sul"; Brasilia, IBRI, Revista Brasileira de Política Internacional, Año 48; No 1, 2005; pp. 29-41. 
económica, el MERCOSUR fue concebido bajo un enfoque esencialmente comercialista, y en sus dos administraciones hubo desinterés por desarrollar con Brasil otras agendas, puesto que sus prioridades de política exterior estaban en la alianza con Estados Unidos?. El MERCOSUR fue un instrumento coyuntural, táctico, de expansión comercial y, más tarde, una instancia hacia la formación del proyecto norteamericano ALCA.

Durante la década de los noventa y hasta entrado el siglo XXI, a pesar de las coincidencias macropolíticas entre Argentina y Brasil dirigidas a la creación de un mercado común, las diferentes estrategias económicas seguidas por ambos países se transformaron en una dificultad para el logro de ese objetivo. Esas diferencias de perspectiva estaban relacionadas con divergencias en la propia visión que cada país poseía en relación a su papel en la comunidad internacional. Brasil alimentó un proyecto de liderazgo regional natural, en tanto Argentina, viéndose a sí misma como un pequeño país en el escenario internacional, dio prioridad a la inserción en el mercado de capitales, ante la evidencia de que esos flujos eran determinantes para su ciclo económico (Baumann, 2001). Esta fue la opción que eligió el gobierno de Carlos Menem (1989-1999), porque su alianza estratégica fue establecida con los Estados Unidos; a partir del reconocimiento a su absoluta hegemonía y compartiendo la visión sobre el orden mundial y la globalización que tenían los Estados Unidos (Bernal-Meza, 2000).

El corto gobierno de De la Rúa (1999-2001), no implicó cambios en la percepciones y objetivos argentinos en el MERCOSUR, en la medida que la presencia de Domingo Cavallo (que había sido ministro de Relaciones Exteriores y luego de Economía bajo las gestiones de Carlos Menem) impulsó incluso reducir el Acuerdo a una simple zona de libre comercio, desechando la construcción de un mercado común. La política exterior, tanto de De la Rúa como de su sucesor, Eduardo Duhalde (2002-2003), estuvo marcada por la tensiones de una no definida opción - entre Estados Unidos o Brasil - y los efectos de una relación triangular que se proyectaba desde fines de los 90's, cuando Argentina - a pesar de su alianza con Estados Unidos - decidió adherir a la visión brasileña de negociar ALCA en el marco de un acuerdo 4+1 (los cuatro países del MERCOSUR, en bloque). La Argentina se mantuvo en las tensiones entre su cercanía política a los Estados Unidos o fortalecer un mayor vínculo con Brasil.

El cambio en la visión política que la Argentina tenía respecto del MERCOSUR y las relaciones con Brasil vino con el gobierno de Néstor Kirchner (2003-2007). La llegada de Lula da Silva con su idea de reforzar el MERCOSUR hizo que la Argentina ganara relevancia estratégica en la agenda brasileña que anteriormente no poseía (Simonoff, 2005: p. 140). Con Kirchner la Argentina se acercó más al Brasil en la visión sobre el regionalismo al cual se aspiraba: entre la propuesta

9 Distintos autores han desarrollado ampliamente estos vínculos; cfr. J. PARADISO (1993); A. BUSSO y B. BOLOGNA (1994); Carlos ESCUDÉ (1995); F. De La BALZE (1998); A. CISNEROS (1998), R. BERNAL-MEZA (2000); M. RAPOPORT (2000); etc. 
norteamericana de ALCA y la integración plena diseñada con el MERCOSUR, ambos países optaron decididamente por la opción sudamericana.

La plataforma de política exterior de Kirchner puso a las relaciones con Brasil y el MERCOSUR como el eje central de sus vinculaciones internacionales: "la profundización del MERCOSUR y la relación con los países asociados, Chile y Bolivia, deben ser nuestras prioridades, sobre la base de relaciones equilibradas e igualitarias entre los países", se leía en sus propuestas de campaña ${ }^{10}$. El MERCOSUR surgió entonces, en la visión del gobierno de Kirchner como un eje que articulaba las negociaciones con otras áreas comerciales (ALCA, Unión Europea, OMC, etc.), perspectiva que coincidía con la que era predominante en el ministerio de Relaciones Exteriores brasileño.

Sin embargo, en las relaciones intra-MERCOSUR fue evidente la aparición de tensiones. El propio impulso de Brasil por cambiar su status-de potencia regional a potencia con intereses globales - generó repercusiones, no sólo en la estructura regional, sino también en la articulación de las estrategias hacia los organismos multilaterales, otros espacios regionales o países donde el MERCOSUR es el eje central de las negociaciones (Simonoff, 2006). La aspiración brasileña de acceder a un asiento permanente en el Consejo de Seguridad de las Naciones Unidas, reflotada por Lula luego que Cardoso la difiriera, frenó las posibilidades de una profundización de las relaciones que los presidentes Lula y Kirchner habían reafirmado como "estratégicas". En efecto, ambos presidentes habían firmado en Río de Janeiro, el 16 de marzo de 2004, el "Acta de Copacabana", por el cual los dos países se comprometían a "profundizar la asociación estratégica y definir una posición convergente en los temas comunes".

Mientras tanto, en Argentina subsistieron, de manera predominante, las percepciones acerca del interés de Brasil por utilizar al MERCOSUR como un elemento de una política de poder y como instrumento de su propia política mundial, lo que ha creado tensiones y diferencias entre ambos, Argentina fue profundizando comercialmente su dependencia del Brasil, hacia donde ha dirigido entre el 30 y el $40 \%$ de sus exportaciones. La extensión del bloque hacia el resto de países sudamericanos, comenzando por la Comunidad Andina de Naciones, que impulsó Lula da Silva, no fue aceptada por Argentina. El gobierno de Néstor Kirchner siempre consideró que debía profundizarse primero el MERCOSUR, antes de avanzar sobre proyectos de integración más extensivos.

Si se observa el escenario sudamericano, Brasil sigue siendo el socio externo más importante para la Argentina. Esto es bueno para el MERCOSUR, porque garantiza la continuidad de la integración. Aún así, las mejores relaciones están con Bolivia y con Venezuela. La relación con este país ha sido para el matrimonio Kirchner una cuestión de pragmatismo. En Caracas coincide la fuente de dos

10 Frente para la Victoria (2003), citado por Alejandro Simonoff, "Estructura y coyuntura en la Politica Exterior de Néstor Kirchner (2003-2005)", en Relaciones Internacionales, La Plata, Instituto de Relaciones Internacionales, Universidad nacional de La Plata, No 31/2006; pp. 133-145. 
de las necesidades estratégicas del desarrollo argentino: provisión energética y financiamiento de corto y mediano plazo. Y frente al la aspiración de Chávez, de presentarse como aspirante al liderazgo sudamericano - espacio por el cual a Néstor Kirchner no le interesó competir, es porque el lugar estaba vacante, por gracia y voluntad de un Brasil ausente.

Respecto del Consejo de Seguridad, la Argentina siempre criticó que hubiera estados con derecho a veto y que existiera una permanencia ininterrumpida de los cinco estados miembros permanentes. La reforma del Consejo de Seguridad, según las autoridades argentinas que tratan estos asuntos, forma parte de un tema muy complejo que debe ser resuelto por consenso. La creación de nuevas bancas permanentes debe ser decidida por cada región sin que altere los equilibrios regionales. La Argentina no apoya la candidatura brasileña. Se considera que lo ideal sería una representación regional dividida y rotativa, una banca semi-permanente.

Con el gobierno de Néstor Kirchner, la posición oficial sigue siendo muy cautelosa, pero reproduce las ideas y percepciones de la tradicional visión argentina, según la cual existe entre ambos países - a pesar de las grandes diferencias geoeconómicas y de poder relativo - una disputa por la posición dominante o representativa de la región. La Argentina sigue desconociéndole - o neg\{andole - a Brasil el derecho a transformarse en el representante permanente de la región dentro del Consejo de Seguridad.

Sin embargo, están las diferencias puntuales y los nuevos recelos en la relación bilateral., los que se han advertido en estos primeros meses de gobierno de la presidenta de la Argentina, Cristina Fernández de Kirchner. Argentina, bajo el gobierno de Néstor Kirchner, se asoció a esa visión brasileña sobre dos tipos de regionalismo (uno al norte y otro al sur de América); pero no parece que su sucesora, Cristina Fernández de Kirchner, coincida en esto. De hecho, en su primera visita a México expresó al presidente Felipe Calderón su deseo de ver a este país integrando el MERCOSUR: un tema al que Brasil se opone totalmente.

Durante estos meses del nuevo gobierno argentino la "agenda MERCOSUR" de Cristina Kirchner ha estado concentrada en promover ante su par brasileño el ingreso de Venezuela y en imponer como prioridad inmediata la cooperación energética. Pero la presidencia pro-témpore que ejerce actualmente la Argentina no ha evidenciado una actividad sostenida en nuevas iniciativas.

\section{Los problemas del desarrollo y la ecuación energética:}

Mientras crecen en Brasil las expectativas respecto de los nuevos yacimientos de petróleo, que colocarían a este país entre los principales productores del mundo, la Argentina se debate en una crisis energética que abarca no sólo los combustibles líquidos, sino el gas y la electricidad.

Asociados ambos países a Bolivia para la provisión de gas - aunque con considerables diferencias (mientras Brasil compra 31 millones de BTU diarios, 
la Argentina recibe sólo 3 de los más de 10 que necesita) - ha sido imposible para Cristina de Kirchner conseguir que Brasil le ceda parte de lo que recibe. Esta situación ha puesto a Venezuela como un nuevo factor de diferencias entre ambos países.

Respecto del papel que podría jugar Venezuela dentro del bloque, el gobierno brasileño es reservado. Brasil se debate entre la aprobación y la cautela ante la intención expresada por Cristina Kirchner de incorporar a Hugo Chávez a la ecuación energética de América Latina, a partir de la adhesión formal de la república bolivariana al bloque. Cristina Kirchner advirtió a Lula que la energía es un problema común, porque Brasil tiene muchos intereses en la industria argentina.

No obstante, el presidente Lula le prometió a la mandataria argentina enviar 200 megavatios cuando el frío aumente la demanda energética argentina. El año pasado Brasil llegó a inyectar hasta 1.000 megavatios al sistema interconectado argentino; un volumen significativamente mayor al que se había comprometido en su momento con Néstor Kirchner.

\section{El presente de las relaciones argentino-brasileñas}

El gobierno argentino actual - tal como su precedente - acepta con resignación el gran activismo internacional que despliega su vecino. Cristina de Kirchner está atada a Brasil en su política internacional. A pesar de las dificultades por obtener de Lula una cooperación en materia gasífera la relación con Brasil sigue siendo la más importante, compleja, extensa y en permanente expansión de la Argentina que con cualquier otro país del mundo.

Tres problemas han afectado las relaciones bilaterales durante los primeros meses de 2008: 1) la cooperación energética, motivada por la crisis que vive la Argentina en este sector estratégico; 2) las ventas de trigo argentino y los condicionamientos brasileños a estas exportaciones; 3) la negociación del nuevo acuerdo bilateral en el sector automotriz.

Desde la óptica brasileña, para superar las dificultades energéticas que atraviesa la región se necesitan "inversiones en forma urgente". En esas inversiones Venezuela podría estar involucrada, ya sea por medio del Banco del Sur o a través de una presencia directa.

El segundo tema es el de las exportaciones de trigo. Ante la incerteza de que la Argentina cumpliera con sus compromisos de exportación a Brasil (y esto antes de la crisis que actualmente afecta la producción agrícola argentina, que ha derivado en un paro que al cierre de este Informe llevaba 20 días), el gobierno de Brasil eliminó unilateralmente el arancel externo común (del 10\%) para la importación de trigo de países no integrantes del Mercosur. Sucede que el socio mayor del bloque cree que la Argentina, el principal proveedor del cereal a su enorme mercado interno, no tendrá suficiente cantidad como para satisfacer todas sus necesidades. La eliminación del arancel, decidida por la Cámara de 
Comercio Exterior (Camex), un organismo interministerial, regirá hasta el 30 de junio o antes si se llega a un volumen de un millón de toneladas. Esa cuota equivale al 10\% del consumo del cereal en Brasil.

El tercer tema es el de los acuerdos en el sector automotriz. Se iniciaron las negociaciones para concertar las nuevas condiciones del Pacto Automotor Común (PAC) que acordaron ambos países y que había entrado en vigencia el 1 de julio de 2006, con vencimiento el próximo 30 de junio.

La tradicional posición brasileña ha sido liberar el intercambio de autos lo antes posible, mientras que la Argentina aspira a postergar ese paso para dar tiempo a sus empresas automotrices para alcanzar un rango de competitividad similar a la de sus pares brasileñas.

El problema más grave del sector automotriz está en el segmento de los autopartistas. Brasil es poderoso en ese rubro y mantiene un importante superávit en su comercio con los socios argentinos. El objetivo del gobierno de Buenos Aires es lograr un equilibrio, ya que el sector automotriz explica el 50\% del déficit comercial argentino con Brasil. El comercio bilateral alcanzó los us\$25.000 millones en 2007; con un défict récord para la Argentina de us $\$ 4.500$ millones.

Dentro de la agenda de negocios y complementaciones comerciales bilaterales, los recientes acuerdos en los sectores nuclear, aeronáutico y de defensa aparecen como los más simbólicos, en la perspectiva de afianzar cada vez más la visión de una sociedad estratégica que superó definitivamente las hipótesis de conflicto bilateral. Todos ellos se agregan a los acuerdos militares firmados en 2005 y 2006, por los cuales se decidió empezar en forma combinada en el segundo semestre de 2009 la producción en serie y la comercialización de un vehículo militar todoterreno liviano, pensado para exploración.

Los acuerdos en el área nuclear reflotaron el viejo sueño argentino de un submarino nuclear. Ambos países convinieron la construcción conjunta de un ejemplar de este poderoso tipo de arma naval. El proyecto contempla que la Argentina aportará su experiencia en la producción del reactor nuclear compacto que propulsará el sumergible, mientras que el Brasil aportará la fabricación de la parte no nuclear, basado en tecnología francesa, y el combustible atómico. Para ello, los dos países acordaron la constitución de una empresa binacional, que producirá el reactor compacto; cuya tecnología se proyectará al uso civil en el futuro; desarrollando pequeñas centrales eléctricas con capacidad para abastecer grandes ciudades.

En el sector aeronáutico, la llegada de la empresa aeronáutica Embraer a la Argentina aparece como el proyecto más ambicioso. La iniciativa tiende a unir a la brasileña Embraer con la ex Área Material Córdoba (la antigua Fábrica Militar de Aviones. El proyecto implica hacer allí partes de los aviones de Embraer 170 y 190, dos aeronaves de transporte comercial, muy vendidas por la empresa brasileña.

El desarrollo de nuevas líneas de cooperación en estos tres sectores parecería en realidad formar parte de una estrategia más amplia por parte del gobierno 
brasileño. En efecto, el 22 de febrero pasado el ministro de Defensa del Brasil, Nelson Jobim, expuso ante su par argentina, Nilda Garré, las líneas principales de una posible unión militar sudamericana. Antes de desembarcar en Buenos Aires, Jobim había pasado por Ecuador, Colombia y Chile, en cuyas capitales relató lo que, según sus propias palabras, "es sólo un bosquejo", el borrador de un objetivo claramente estratégico.

Jobim expresó que "estamos haciendo un estudio muy profundo de un proyecto estratégico de la defensa; creemos que no es un tema de nuestro país solamente, sino de la región. Debemos tener una sola voz en América del Sur, pero ningún país tiene el poder para hablar por sí solo por la región. Vamos a presentar la propuesta en la reunión de ministro de Defensa de la Comunidad Sudamericana"

Con el Tratado Interamericano de Asistencia Recíproca (TIAR) como instrumento fuera de época - un pacto del cual Argentina descree desde la guerra de Malvinas-, Brasil procura armar una nueva política de defensa regional, apoyado en su fortaleza económica, diplomática y militar. Sin embargo, las megacompras de material militar en las que se embarcó el gobierno de Lula desde 2005, preocupan a las autoridades argentinas, las cuales esperaron sin éxito explicaciones por parte del propio Lula.

Los ministro de Defensa deBrasil y Argentina acordaron impulsar el Consejo Sudamericano de Defensa, cuya constitución se podría hacer en Brasilia en el mes de octubre próximo. Según voceros militares argentinos, el plan brasileño - con el apoyo de la Argentina - busca unificar criterios de defensa en la región sudamericana y apuesta a crear las bases de una industria de defensa sudamericana; aunque la principal oposición regional podría venir de Colombia.

\section{Las visiones del socio a uno y otro lado}

Mientras en Argentina se pueden advertir dos visiones sobre las relaciones con Brasil, en este último país las percepciones sobre Argentina son más homogéneas.

En Argentina, en especial en el ámbito de la Cancillería, las percepciones sobre Brasil son más bien críticas. Ellas están centradas en dos aspectos: 1) la identificación de cuatro principales problemas: la modificación de sus criterios sobre la integración; la diferente jerarquía constitucional de las normas jurídicas que se relacionan con la institucionalidad del MERCOSUR; las desigualdades en productividad de los respectivos sectores industriales, con su impacto sobre el comercio bilateral - y el déficit argentino - ; y la convicción acerca de que Brasil estaría negociando acuerdos comerciales con la Unión Europea al margen de la fórmula " $4+1$ " acordada por el MERCOSUR; 2) la creencia de que el gobierno de Lula está aceptando la visión realista de Itamaraty, según la cual - por su propio peso específico - Brasil es un actor global que tiene capacidad autónoma 
de negociar en ámbitos bilaterales (con la Unión Europea, en cuestiones que no atañen específicamente al comercio) y multilaterales (Cumbre del Grupo de los Cuatro en Potsdam -Estados Unidos, Unión Europea, India y Brasil - destinada a destrabar las negociaciones en la OMC).

Reaccionando a las críticas, la visión del Ministerio de Relaciones Exteriores del Brasil (Itamaraty) es que la estrategia del país apunta a negociar acuerdos de libre comercio o de preferencias comerciales con países desarrollados (como por ejemplo la Unión Europea) y con algunos países en desarrollo (como India y África del Sur) para conseguir apertura de mercados y de negociación en conjunto, que favorecerían a los países pequeños del MERCOSUR, en la medida que éstos no tienen condiciones de acceso si negocian de manera independiente.

Esta argumentación busca justificar las iniciativas independientes que ha impulsado Brasil en el último tiempo, pero que se agregan a una serie de propuestas que Brasilia lanzó por fuera del MERCOSUR y sin siquiera consensuarlas ni informar previamente a los gobiernos argentinos, como por ejemplo, el lanzamiento de la propuesta de ALCSA, por parte de Itamar Franco, la iniciativa IIRSA de F.H. Cardoso o la propuesta sobre la Comunidad Sudamericana de Naciones y la Cumbre con los países árabes, impulsadas bajo la gestión de Lula.

\section{La visión brasileña sobre Argentina, Venezuela y el MERCOSUR}

Gran parte de la academia brasileña de relaciones internacionales coincide con un sector, aún mayoritario, dentro de Itamaraty, en el sentido de considerar que Argentina es y seguirá siendo el socio estratégico más importante en América del Sur, cuya relación hay que cuidar. Se dice: "Venezuela, para Brasil es importante, muy importante, pero más que todo la prioridad estratégica para Brasil es la Argentina”.

En Brasil se observa a Argentina como un país temeroso de la hegemonía brasileña. Con las condiciones de estrecha cooperación creadas desde la formación del MERCOSUR, Argentina dejó de temer una invasión brasileña; pero "la sombra, real o inventada del liderazgo regional de Brasil" continúa en las percepciones argentinas.

La posición oficial del actual gobierno de Luiz Inácio da Silva asegura, por otra parte, que Brasil sí está preparado para asumir los costos y las responsabilidades que demanden el hecho de tener un asiento permanente en el Consejo, si la comunidad internacional así lo dispone. El actual presidente brasileño ha dado señales concretas de que Brasil va a pasar a tener una acción más activa en la región, asumiendo un papel de liderazgo que Itamaraty venía históricamente rechazando. Sin embargo, aseguran, no se trata de un punto de inflexión radical. Se pretende construir un nacionalismo moderno, que tenga en consideración el papel hegemónico de los Estado Unidos en el mundo, pero que intente ampliar 
los espacios de actuación de Brasil para aumentar su capacidad de negociación.

En ese próximo documento, Samuel Pinheiro Guimarães señala que: "A América do Sul encontra-se, necessária e inarredavelmente, no centro da política externa brasileira. Por sua vez, o núcleo da política brasileira na América do Sul está no Mercosul. E o cerne da política brasileira no Mercosul tem de ser, sem dúvida, a Argentina. Qualquer tentativa de estabelecer diferentes prioridades para a política externa brasileira, ou mesmo a atenção insuficiente a esses fundamentos, certamente provocará graves conseqüências e causará sério risco de fracasso.

"O Brasil, apesar de ser o maior país da região, não acredita ser possível desenvolver-se isoladamente sem que toda a região se desenvolva econômica e socialmente e se assegure razoável grau de estabilidade política e segurança. Assim, a solidariedade nos esforços de desenvolvimento e de integração é uma idéia central na estratégia brasileira na América do Sul."

"A coordenação política que ocorre entre a Argentina e o Brasil na defesa de seus interesses nos foros, nas negociações, nos conflitos e nas crises internacionais atingiu nível de extraordinária intensidade e eficiência e foi isto que nos permitiu agir no âmbito da negociações hemisféricas desiguais e no âmbito das negociações multilaterais econômicas de modo a impedir o desequilíbrio de seus resultados e a garantir o espaço necessário às nossas políticas de desenvolvimento econômico.”

\section{La visión argentina}

La entrada de Brasil en el grupo de "socios estratégicos" de la Unión Europea, ha suscitado algún recelo entre el resto de los países que integran MERCOSUR y, de manera clara (aunque no tan explícita) en el gobierno argentino, que temen el establecimiento de compromisos políticos y comerciales sobre una base bilateral, sin que el resto de socios esté implicado. No obstante hay importantes diplomáticos argentinos que consideran que esa categoría no tiene elementos profundos.

Sin embargo, Argentina - y en esto ha habido coincidencias desde el gobierno del ex presidente Menem hasta el presente - ha considerado que la fortaleza del MERCOSUR radicará siempre en presentarse internacionalmente como una sola voz, consensuada entre todos los soios.

\section{Conclusiones: el MERCOSUR y su situación actual - una sensación de estancamiento}

En los cuatro países del MERCOSUR existe actualmente una percepción que habla de un estado de estancamiento y deterioro del proceso de integración.

¿Por qué la iniciativa regional del Cono Sur se fue debilitando y creció el inconformismo sobre el MERCOSUR?

Debe tenerse en cuenta que las estrategias de integración y cooperación que siguen los países no pueden ser analizadas en abstracto, descontextualizadas de 
su naturaleza de origen. Ellas deben ser puestas contra el telón de fondo de la política exterior - porque ella es una e indivisible - y contrapuestas al modelo de desarrollo o inserción internacional de cada país.

En estos dos aspectos, política exterior y modelo de desarrollo o inserción internacional, los países fueron diferenciándose. En política exterior, las relaciones con Estados Unidos, las posiciones vis-á-vis las estrategias norteamericanas (ALCA; acuerdos bilaterales) resultaron ser un factor de enorme peso para la mayoría de los países y también un considerable factor de diferenciación y alejamiento. Por su parte, los modelos de desarrollo o inserción internacional, que tenían que ver con el grado de apertura económica (ámbitos comerciales y financieros) fueron otro factor de enorme diferenciación.

Así llegamos a que en la región sudamericana nos encontráramos con cuatro modelos de política comercial y arancelaria: MERCOSUR, Comunidad Andina de Naciones; países miembros de la CARICOM (Suriname y Guyana) y Chile. En ese contexto, era muy difícil poder concertar un modelo de integración, de arancel externo, de tratamiento a los capitales extranjeros y a la inversión, etc. que fuera homogéneo para tan significativas diferencias nacionales.

Pero respecto a la visión sobre la política mundial, la lectura sobre el proceso de globalización, cuestiones que remiten a la aceptación o no de las políticas mundiales impulsadas por Estados Unidos y sus principales aliados, han tenido también en nuestra región su correlato: entre el rechazo y la aceptación. Un ejemplo de esto es la posición frente a la apertura, tanto comercial y financiera, como política - en relación a los principales temas de la agenda global impulsada por las grandes potencias occidentales-. Mientras unos países se han mostrado receptivos, como Colombia, Chile y Perú, otros han sido más reservados, como Brasil y Uruguay, en tanto otro grupo ha sido considerablemente más crítico, como Argentina, Bolivia y Venezuela.

Sin embargo, esto no alcanza para explicarse ese debilitamiento y tampoco para justificar las nuevas iniciativas, que fueron desplazando el interés por la integración económica hacia la cooperación, más laxa y flexible. Esto se explica por el cambio de prioridades y objetivos ocurridos dentro de la política exterior del principal país de la región: Brasil.

En su afán por establecer dos ámbitos regionales de influencia en el hemisferio, uno al Norte, en torno de Estados Unidos, que agrupara a América del Norte, Central y el Caribe y otra en América del Sur, que girara en torno a la influencia brasileña, este país debió enfrentarse a la necesidad de modificar su política.

Un tercer aspecto, también vinculado con la política exterior del Brasil, tiene que ver con sus recuperados y aggiornados intereses "globales": Consejo de Seguridad de Naciones Unidas y Organización Mundial de Comercio (y relaciones Estados Unidos/Europa vis-á-vis los países en desarrollo). En su actualizada visión realista de la política mundial, Brasil advirtió que los problemas - principalmente con Argentina - para conducir al MERCOSUR hacia un grado 
de profundización compatible con sus macro-percepciones, que le permitieran presentarse en el ámbito internacional como el líder indiscutido y no cuestionado de la sub-región (en torno de la cual deberían girar o integrarse los restantes esquemas de integración existentes), eran lo suficientemente importantes que le dificultarían enormemente el objetivo de instrumentalizarlo en su beneficio político. Entonces, decidió dirigir su interés preferencial hacia otro instrumento, que yacía latente desde que lo lanzara F.H. Cardoso en el año 2000: la Comunidad Sudamericana de Naciones; hoy UNASUR.

Brasil pudo haber hecho avanzar el MERCOSUR e, incluso, haberlo hecho funcional a sus grandes objetivos de política mundial - ser considerado como una indiscutida potencia regional - pero no estuvo dispuesto a pagar el costo. Faltos de una visión estratégica de largo plazo, la dirigencia política y los grupos de poder brasileños han creído que se puede alcanzar el liderazgo y la hegemonía sin pagar costos económicos. En eso se equivocaron. Leyeron mal la historia de las relaciones internacionales. La racionalidad que conlleva el concepto de hegemonía es hacer creer a los demás que el líder ejecuta sus políticas en beneficio de todos. Llevando esta lógica al MERCOSUR y a Sudamérica en general: ¿dónde está esa percepción por parte de los países sudamericanos?

La llegada al gobierno de coaliciones como la de Evo Morales y ahora la futura de Fernando Lugo en Paraguay, han puesto en el centro del cuestionamiento la política que Brasil ha seguido respecto del aprovechamiento y explotación de los recursos naturales de esos pequeños países. Hoy el gobierno de Lula está tratando de despegarse de una visión imperialista con la que se asocia al Brasil. Es bueno que lo haga porque, en primer lugar, no ha sido la política que su gobierno implementó, sino que la recibió del pasado; pero, en segundo lugar, porque no habrá escenario regional cómodo y estable para Brasil si estas injusticias no se resuelven.

Argentina y Brasil han tenido significativas diferencias en su política exterior, desde que ambos países retornaron a la democracia, a mediados de la década de 1980.

Brasil mantuvo una línea de constante activismo, sostenido en el paradigma del idealismo kantiano bajo Cardoso y del realismo del poder bajo Lula, los paradigmas de política exterior de la Argentina han marcado ese camino de distanciamiento y alineamiento: "Tercera Posición" (1949-1955) y "Autonomía Heterodoxa” (1973-1976), en el primer caso; "Realismo Periférico” (1989-2001), en el segundo. ${ }^{11}$

El objetivo de reconocimiento internacional a su condición de "potencia regional" ha perneado la política exterior del Brasil y sus objetivos, desde fines de los años 70's. A pesar de sus dimensiones y de ser la octava economía del mundo,

11 Para un análisis más amplio y comparativo de los paradigmas de política exterior de la Argentina, cfr: Raúl BERNAL-MEZA (1994; 2003; 2005). 
existe una diferencia - que la dirigencia brasileña ha percibido en toda su rudeza: entre la percepción generalizada en la comunidad occidental y dentro del Tercer Mundo, en el sentido que Brasil debería jugar un papel más relevante en los asuntos mundiales y la realidad de que aún no es, reconocidamente, un jugador importante de la política mundial. Sin embargo, está en camino de lograrlo, gracias a sus liderazgos en el G-20 y en el G-4, pero no ha podido incorporar en éstos al MERCOSUR.

La persistencia del Brasil a utilizar el MERCOSUR como instrumento de su propia estrategia de poder internacional y su negativa a pagar costos económicos por su liderazgo, a través de la cooperación energética, por ejemplo, han llevado al gobierno de la nueva presidenta argentina, Cristina de Kirchner, a profundizar sus lazos económicos con Venezuela y retomar los vínculos bilaterales con México. De hecho, la actual presidenta argentina se ha caracterizado por su fuerte apoyo a Venezuela para su ingreso al MERCOSUR - objetivo no deseado completamente por Brasil - y señalado su deseo de ver a México integrar el bloque, a lo que Brasil se opone rotundamente.

Con un Brasil decididamente volcado a asumir el papel de potencia regional, Argentina, habiendo abandonado el activismo y las aspiraciones a un liderazgo internacional de la mano de Estados Unidos, como el que caracterizó en los 90's las presidencias de Carlos Menem, con Néstor Kirchner no mostró, en ningún momento, una predisposición a competir con Brasil por el liderazgo sudamericano. Ese lugar lo ocuparía Chávez.

Para el Brasil, el MERCOSUR fue siempre un instrumento de realpolitik y que los Estados Unidos percibieron como un desafío. La potencia hegemónica nunca aceptó la existencia de este proyecto de integración que competía con sus estrategias hemisféricas.

Para Argentina, el rol del MERCOSUR en el ámbito de una economía mundial cada vez más complicada por las políticas de los principales países desarrollados y el estancamiento de las negociaciones multilaterales en la OMC es de vital importancia. En un escenario comercial mundial de incertidumbre, en las clases dirigentes de poder de la Argentina hay actualmente una convicción profunda de que no existe la posibilidad de la inserción argentina en el mundo si no es con una alianza estratégica con Brasil.

Si bien se advierten diferencias entre ambos países, que afectan cuestiones de índole económica, comercial y política - tanto a nivel bilateral como en el marco del MERCOSUR - hay posiciones predominantes que coinciden en la necesidad de preservar la relación estratégica entre las dos mayores naciones sudamericanas.

Argentina y Brasil tienen problemas comunes. Entre éstos está el energético. Tanto uno como el otro enfrentan hoy una crisis en el sector y una creciente demanda que, en el corto y mediano plazo se verá insatisfecha si se restringe la búsqueda de respuestas a los límites territoriales de las dos economías. Esto queire 
decir que ambos necesitan fortalecer los vínculos cooperativos y de integración con los dos países que hoy cuentan con las principales reservas probadas de gas y petróleo en la región: Venezuela y Bolivia.

La definición de "socio estratégico", asignada por la Unión Europea a Brasil es, por ahora, sólo un valor asociado a los aspectos políticos. Pero, sin embargo, no ha dejado de desatar en Argentina discusiones respecto del papel que Brasil pretende jugar en Sudamérica y, particularmente, en el MERCOSUR.

Tres escenarios de integración ahora confrontan en Sudamérica: el MERCOSUR, más importante para Argentina; la UNASUR, hoy tal vez el proyecto que más interesa a Brasil; y ALBA, la Alternativa Bolivariana de Integración, promovida por el presidente Chávez, de la que sólo Bolivia hace parte junto a Venezuela.

En este escenario, los objetivos del Brasil, de tener una región homogénea sobre la cual pueda ejercer su hegemonía, parecen estar destinados al fracaso.

Recebido em 30 de janeiro de 2008 Aprovado em 30 de agosto de 2008

\section{Bibliografía}

BALASSA Bela (1980). Teoría de la Integración Económica, México, UTEHA.

BAUMANN, Renato \{organizador\}, (2001), MERCOSUR. Abanicos e desafíos da integração, Brasilia, IPEA/CEPAL.

BERNAL-MEZA, Raúl (1994), América Latina en la Economía Política Mundial, Buenos Aires, Grupo Editor Latinoamericano.

BERNAL-MEZA, Raúl (1998), "As relações entre Argentina, Brasil, Chile e Estados Unidos: política exterior e MERCOSUL", en Revista Brasileira de Política internacional, Brasilia, Intituto Brasileiro de Relações Internacionais; Año 41, No 1, 1998; pp.89-107.

BERNAL-MEZA, Raúl (1999). Políticas exteriores comparadas de Argentina e Brasil rumo ao Mercosul. Rev. bras. polít. int. , Brasília, v. 42, n. 2, 1999. Disponível em: <http://www. scielo.br/scielo.php? script $=$ sci_arttext $\&$ pid $=$ S0034-73291999000200003\&lng $=\& \mathrm{nrm}=\mathrm{iso}>$. Acesso em: 022008.

BERNAL-MEZA, Raúl (2000), Sistema Mundial y MERCOSUR. Globalización, Regionalismo y Políticas Exteriores Comparadas, Buenos Aires, Nuevohacer/Universidad Nacional del Centro de la Provincia de Buenos Aires.

BERNAL-MEZA, Raúl (2001), "El MERCOSUR y las contradictorias politicas de Argentina y Brasil”, en Carta Internacional, São Paulo, USP-Política Internacional e FUNAG; Año IX, No 102, agosto 2001; pp. 7-10.

BERNAL-MEZA, Raúl (2002(. A política exterior do Brasil: 1990-2002. Rev. bras. polít. int. , Brasília, v. 45, n. 1, 2002. Disponível em: <http://www.scielo.br/scielo.php?script=sci_ arttext\&pid=S0034-73292002000100002\&lng=\&nrm=iso >. Acesso em: 022008. 
BERNAL-MEZA, Raúl (2003), "Venturas y desventuras de la Argentina: los cambios de paradigma de política exterior y su relación con los modelos de inserción”, en Estevão Chaves de Rezende MARTINS, Relações Internacionais. Visōes do Brasil e da América Latina, Brasilia, Instituto Brasileiro de Relações Internacionais y Fundação Alexandre de Gusmão; pp. 287-318.

BERNAL-MEZA, Raúl (2005), América Latina en el mundo. El pensamiento latinoamericano y la teoría de relaciones internacionales, Buenos Aires, Nuevohacer/Grupo Editor Latinoamericano.

BERNAL-MEZA, Raúl (2006), "Cambios y continuidades en la política exterior brasileña”, en Lateinamerika Analysen, Hamburgo, Institut für Iberoamerika-Kunde, No 13, Februar 2006; pp. 69-94.

BERNAL-MEZA, Raúl (2007), “Cambios y continuidades en la política exterior brasileña. El Consejo de Seguridad: ¿El retorno del Realismo? Sus impactos en el Cono Sur”; en Ségio COSTA, Harmut SANGMEISTER, Sonja STECKBAUER (Orgs.), O Brasil na América Latina. Interaçôes, percepçôes, interdependencias, Sâo Paulo, ANNABLUMA Editora, 2007; pp. 11-38.

BERNAL-MEZA, Raúl y MASERA, Gustavo (2008), "El retorno del regionalismo. Aspectos politicos y económicos en los procesos de integración internacional"; Mendoza, mimeo.

BUSSO, Anabella y BOLOGNA, Alfredo Bruno (1994), "La politica exterior argentina a partir del gobierno de Menem. Una presentación”, en CERIR, La política exterior del gobierno de Menem. Seguimiento y reflexiones al promediar su mandato, Rosario, Centro de Estudios en Relaciones Internacionales de Rosario, CERIR; pp. 17-51.

CERVO, Amado Luiz (2002). Relações internacionais do Brasil: um balanço da era Cardoso. Rev. bras. polít. int. , Brasília, v. 45, n. 1, 2002. Disponível em: <http://www.scielo.br/scielo. php? script $=$ sci_arttext \&pid $=$ S0034-73292002000100001\&lng=\&nrm=iso $>$. Acesso em: 022008.

CERVO, Amado Luiz (2007). Inserçâo Internacional. Formaçâo dos conceitos brasileiros, Sâo Paulo, Editora Saraiva.

CISNEROS, Andrés \{comp\}, (1998), Política exterior Argentina 1989-1999. Historia de un éxito, Buenos Aires, CARI/Nuevohacer, Grupo Editor Latinoamericano.

De La BALZE, Felipe A.M. (1998), La política exterior de reincorporación al Primer Mundo", en Andrés CISNEROS (1998); pp. 107-178.

ESCUDÉ, Carlos (1995), El Realismo de los Estados débiles. La política exterior del primer gobierno Menem frente a la teoría de las relaciones internacionales; Buenos Aires, Grupo Editor Latinoamericano.

HURRELL, Andrew (1994): “Regionalismo en las Américas", en LOWENTHAL, Abraham y TREVERTON, Gregory (comps.), América Latina en un Mundo Nuevo, México D.F., Fondo de Cultura Económica; pp. 199-226.

LESSA, Antônio Carlos (1998). A diplomacia universalista do Brasil: a construção do sistema contemporâneo de relações bilaterais. Rev. bras. polít. int. , Brasília, v. 41, n. spe, 1998. Disponível em: <http://www.scielo.br/scielo.php?script=sci_arttext\&pid=S0034$73291998000300003 \& \operatorname{lng}=\& n r m=i s o>$. Acesso em: 022008.

LIMA, Maria Regina Soares de (2005). A política externa brasileira e os desafios da cooperação Sul-Sul. Rev. bras. polít. int. , Brasília, v. 48, n. 1, 2005. Disponível em: <http:/www.scielo.br/ 
scielo.php? script $=$ sci_arttext $\&$ pid $=S 0034-73292005000100002 \& \operatorname{lng}=\& \mathrm{nrm}=\mathrm{iso}>$. Acesso em: 02 2008. doi: 10.1590/S0034-73292005000100002.

PARADISO, José (1993), Debates y trayectoria de la política exterior argentina, Buenos Aires, Grupo Editor Latinoamericano.

RAPOPORT, Mario y colab. (2000), Historia económica, social y política de la Argentina (1880-2000), Buenos Aires, Ediciones Macchi.

SARAIVA, Miriam Gomes (2007). As estratégias de cooperação Sul-Sul nos marcos da política externa brasileira de 1993 a 2007. Rev. bras. polít. int. , Brasília, v. 50, n. 2, 2007. Disponível em: <http://www.scielo.br/scielo.php?script=sci_arttext $\&$ pid $=$ S0034$73292007000200004 \& \operatorname{lng}=\& \mathrm{nrm}=\mathrm{iso}>$. Acesso em: 02 2008. doi: 10.1590/S003473292007000200004 .

SIMONOFF, Alejandro (2005), "Envio de Tropas y Politica Exterior (1989-2005)", en Relaciones Internacionales; IRI La Plata, No 28, 2005, pp. 127-159.

SIMONOFF, Alejandro (2006), "Estructura y coyuntura en la politica exterior de Néstor Kirchner”, en Relaciones Internacionales, IRI, La Plata, No 31, 2006; pp. 133-145.

SOUTO MAIOR, Luiz A. P. (2006). O Brasil e o regionalismo continental frente a uma ordem mundial em transição. Rev. bras. polít. int. , Brasília, v. 49, n. 2, 2006. Disponível em: <http://www.scielo.br/scielo.php?script=sci_arttext\&pid=S0034$73292006000200003 \& \operatorname{lng}=\& \mathrm{nrm}=\mathrm{iso}>$. Acesso em: 02 2008. doi: 10.1590/S003473292006000200003 .

VAZ, Alcides Costa (1999). Parcerias estratégicas no contexto da política exterior brasileira: implicações para o Mercosul. Rev. bras. polít. int. , Brasília, v. 42, n. 2, 1999. Disponível em: <http://www.scielo.br/scielo.php?script=sci_arttext\&pid=S0034$73291999000200004 \& \operatorname{lng}=\& \mathrm{nrm}=\mathrm{iso}>$. Acesso em: 022008.

\section{Resumo}

Este artículo analiza la política de Brasil y Argentina en relación a los procesos de integración y cooperación regionales, en particular hacia el Mercosur. Se hace previamente una reflexión teórica sobre la regionalización o regionalismo, luego se presenta someramente el Mercosur para en seguida abordar las respectivas políticas exteriores. En Sudamérica el Mercosur coexiste hoy con otras dos iniciativas. Como nuevos escenarios de regionalización aparecen, desde diciembre de 2004 la Unasur (Unión Sudamericana de Naciones) como esquema de cooperación y concertación liderado por Brasil y, desde la misma época, ALBA (Alternativa Bolivariana de Integración) promovida por el presidente Chávez como proyecto contrario al Mercosur, al cual considera "neoliberal".

\section{Abstract}

This article analyzes the politics of Brazil and Argentina in the relation of the regional integration and cooperation process, stressing the Mercosur. Firstly a theoretical reflection about the regionalism, Secondly a concise explanation about the Mercosur, them discuss the respective external politics. In South America the Mercosur coexist along other initiative. As new regionalism scenarios appears since December 2004, the Unasur (Union of South 
American nations) such a cooperation and agreement plan leadership by Brazil and, from the same time, ALBA (Bolivarian alternative of integration) promoted by the president Chavéz by a project against the Mercosur, which he considered "neoliberal".

Palavras-chave: Argentina, Brasil, América del Sur, Unasul, Mercosur, Integración Regional. Key words: Argentina, Brasil, South America, Unasul, Mercosul, Regional Integration. 